\title{
An Experimental and Numerical Study of Tip Vortex Cavitation
}

\author{
J.A. Szantyr, Prof. \\ P. Flaszyński, Ph. D. \\ K. Tesch, Ph. D. \\ Gdansk University of Technology \\ W. Suchecki, Ph. D. \\ S. Alabrudziński, Ph. D. \\ Warsaw University of Technology
}

\begin{abstract}
The article presents the results of the research project concerning tip vortex cavitation. This form of cavitation is very important in operation of many types of rotary hydraulic machines, including pumps, turbines and marine propellers. Tip vortex cavitation generates noise, vibration and erosion. It should be eliminated or significantly limited during the design of these types of machines. The objective of the project was to develop an accurate and reliable method for numerical prediction of tip vortex cavitation, which could serve this purpose. The project consisted of the laboratory experiments and numerical calculations. In the laboratory experiments tip vortex cavitation was generated behind a hydrofoil in the cavitation tunnel and the velocity field around the cavitating kernel was measured using the Particle Image Velocimetry method. Measurements were conducted in three cross-sections of the cavitating tip vortex for a number of angles of attack of the hydrofoil and for several values of the cavitation index. In the course of numerical calculations two commercial CFD codes were used: Fluent and CFX. Several available approaches to numerical modeling of tip vortex cavitation were applied and tested, attempting to reproduce the experimental conditions. The results of calculations were compared with the collected experimental data. The most promising computational approach was identified.
\end{abstract}

Keywords: rotary hydraulic machinery; cavitation; numerical methods; experimental techniques

\section{INTRODUCTION}

One of the most important problems in design of different types of rotary hydraulic machines, such as marine propellers, water turbines and pumps is the as accurate as possible prediction of cavitation properties of these machines. Such a prediction enables elimination or significant limitation of the cavitation phenomena at the design stage. Among different types of cavitation, the tip vortex cavitation plays a very important role, because it is responsible for generation of intensive noise and vibration and also often causes erosion of the machinery elements. Development of accurate and reliable method for numerical prediction of tip vortex cavitation is the objective of research described below.

The mechanism of formation of the cavitating tip vortex is shown schematically in Fig. 1. Combination of the inflow velocity to the hydrofoil and intensive rotation of the liquid around the vortex leads to the region of strongly reduced pressure, with minimum at the centre of the vortex just behind the tip of the foil. The complicated contradictory phenomena of concentration and dissipation of vorticity plays an important role in this process. Cavitation nuclei, i.e. micro-bubbles naturally present in the liquid, are pushed by the pressure distribution into the centre of the vortex, where in sufficiently low pressure they undergo rapid growth, leading to formation of the cavitating kernel of the vortex.

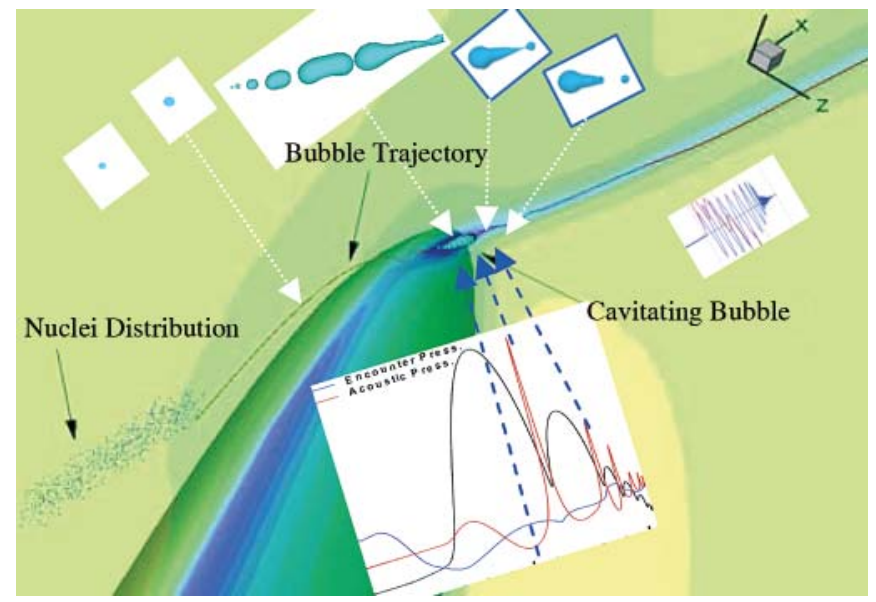

Fig. 1. Scheme of formation of the cavitating tip vortex 
The accurate determination of the pressure distribution in close vicinity of the tip vortex is the obvious pre-requisite for effective prediction of the tip vortex cavitation. The methods for calculation of the velocity and pressure around a tip vortex were the subject of earlier research published in $[1,2,3,6]$.

The continuation research, presented in this article, consists of the experimental and numerical parts. The purpose of the experimental part is to supply information about the velocity field around the cavitating tip vortex, necessary for development of the numerical methods and data concerning the geometry of the cavitating vortex for experimental verification of the numerical results. In the numerical part of the research project two commercial computer CFD codes were used and several available models of turbulence were tested. The detailed presentation of the experimental and numerical research is included in the following sections of the article.

\section{EXPERIMENTAL MEASUREMENTS OF THE VELOCITY FIELD AROUND THE CAVITATING TIP VORTEX}

The experiments were conducted in the cavitation tunnel of the Department of Energy and Industrial Apparatus of the Gdansk University of Technology, shown in Fig. 2. This tunnel has a rectangular measuring section having the dimensions $3.0 * 0.35 * 0.45$ meters. The maximum flow velocity in the tunnel is 6 meters per second. The velocity measurements around the cavitating tip vortex were performed using the Particle Image Velocimetry method and they were conducted by the team from the Warsaw University of Technology, Faculty of Civil Engineering, Mechanics and Petrochemistry. The PIV equipment set-up is also shown in Fig. 2.

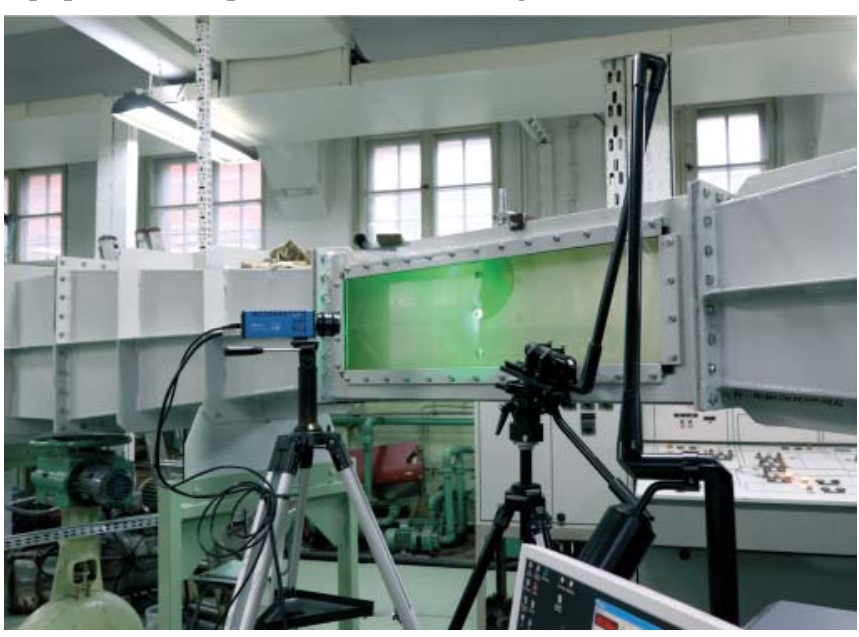

Fig. 2. Cavitation tunnel during PIV measurements

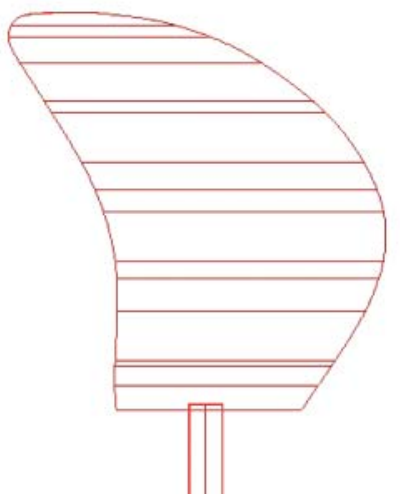

The hydrofoil model used in the experiments was specially designed on the basis of the typical contemporary marine propeller blade geometry, which was developed onto a plane surface (cf. Fig. 3). The span of the hydrofoil was selected equal to $225 \mathrm{~mm}$ in order to ensure that the cavitating tip vortex was located approximately in the centre line of the measuring section. The hydrofoil was manufactured of bronze and mounted vertically in the tunnel by means of the mechanism enabling accurate control of the angle of attack.

The PIV measurements were conducted for a number of conditions, resulting from combinations of angle of attack and flow velocity. These conditions are listed in Table 1, together with the locations of three measurement planes. These planes were perpendicular to the tunnel axis and they were located 50,200 and $300 \mathrm{~mm}$ behind the tip of the hydrofoil, in order to visualize the process of development of the cavitating tip vortex. The combination of all conditions listed in Table 1 produced 27 measurements of flow velocity (3 velocities* 3 angles of attack $* 3$ measuring planes). During the experiments the static pressure in the tunnel was kept constant at $15[\mathrm{kPa}]$ and the variation in the cavitation index were obtained through changes in the flow velocity. The cavitation index $\sigma$ is defined according to the formula:

$$
\sigma=\frac{p-p_{v}}{\frac{1}{2} \rho V^{2}}
$$

where:

$\mathrm{p} \quad-\quad$ the static pressure in the tunnel

$\mathrm{p}_{v}-$ the critical vapour pressure

$\rho \quad-$ the liquid density

$\mathrm{V}$ - the flow velocity

Tab. 1. Conditions for PIV measurements

\begin{tabular}{|c|c|c|c|}
\hline $\begin{array}{c}\text { Distance } \\
\text { behind the } \\
\text { hydrofoil } \\
\text { tip } \\
{[\mathbf{m m}]}\end{array}$ & $\begin{array}{c}\text { Flow } \\
\text { velocities } \\
{[\mathbf{m} / \mathbf{s}]}\end{array}$ & $\begin{array}{c}\text { Cavitation } \\
\text { indices } \\
{[-]}\end{array}$ & $\begin{array}{c}\text { Angles } \\
\text { of } \\
\text { attack } \\
\text { [deg] }\end{array}$ \\
\hline 50 & $4.32,5.09,5.87$ & $1.393,1.003,0.755$ & $4,8,12$ \\
\hline 200 & $4.32,5.09,5.87$ & $1.393,1.003,0.755$ & $4,8,12$ \\
\hline 300 & $4.32,5.09,5.87$ & $1.393,1.003,0.755$ & $4,8,12$ \\
\hline
\end{tabular}

PIV method enables determination of the velocity vectors on the basis of measurement of displacement of particles between two correlated pictures created by the laser light (cf. Fig. 5) and registered consecutively in a short time interval

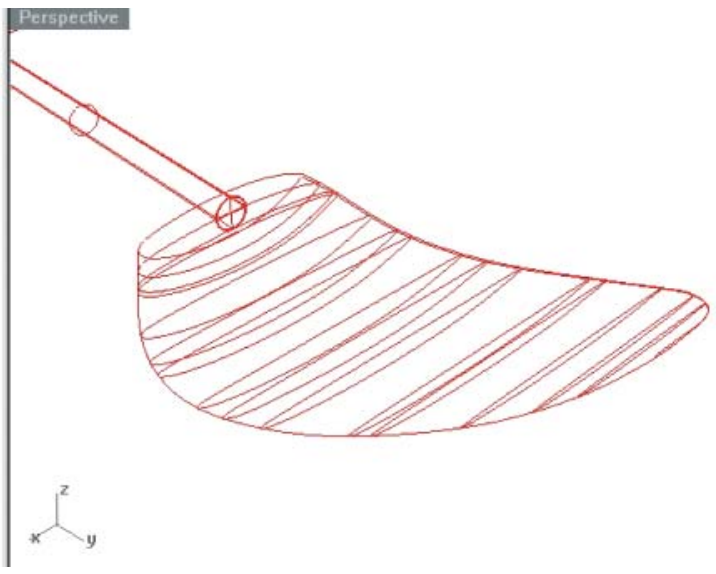

Fig. 3. Design of the model hydrofoil 
by the camera. In order to provide sufficient number of microparticles in the flow, necessary for effective PIV measurements, the water in the tunnel was seeded with a silver metallic paint. The deflection of the light beam when crossing the windowwater boundary was taken into account. The results of PIV measurements were stored in computer files and then filtered and re-calculated using specialized software.

The scheme of the PIV measuring system is shown in Fig. 4. The distances of the camera $\mathrm{K}$ from the measuring section were kept constant $\mathrm{b}=570 \mathrm{~mm}$ and $\mathrm{c}=668 \mathrm{~mm}$. The distance of the laser $\mathrm{L}$ from the measuring section was constant and equal to $\mathrm{a}=440 \mathrm{~mm}$. The distances of the measuring plane from the hydrofoil tip were varied: $d=50,200$ and 300. The system was arranged in such a way that the angle between the laser light plane and the camera axis was approximately equal to 45 degrees in all measurements.

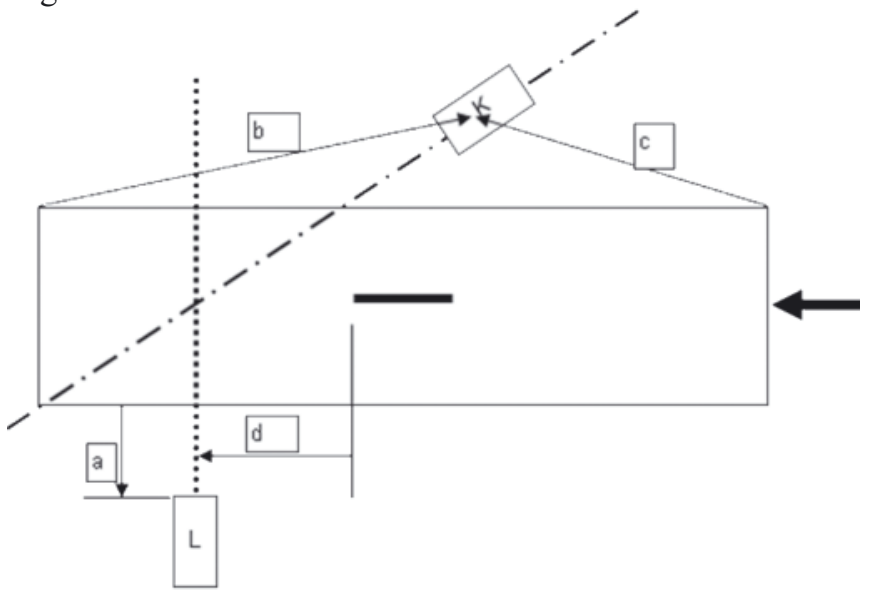

Fig. 4. Scheme of the measuring system

Fig. 5 shows the laser light in the measuring plane $50 \mathrm{~mm}$ behind the hydrofoil tip during the PIV measurements. Apart from the PIV measurements the photographic registration of the cavitating tip vortex was performed. The complete description of the measurements may be found in [5].

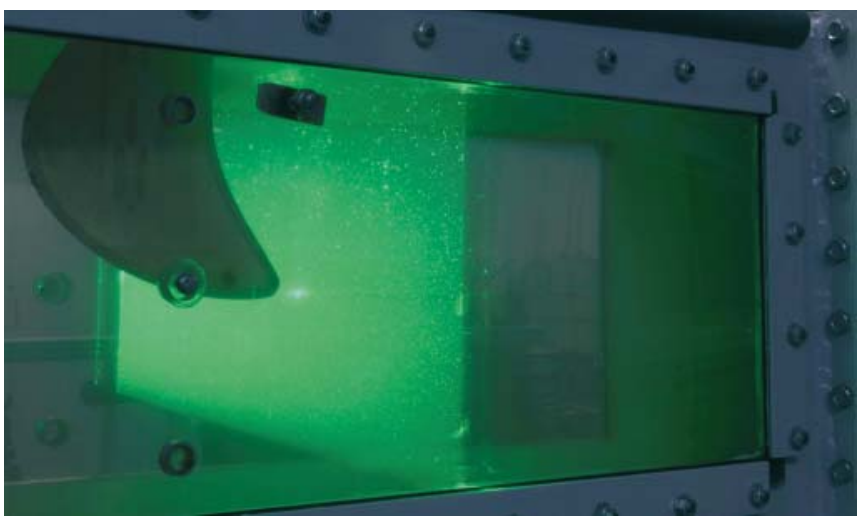

Fig. 5. The PIV measurement plane behind the tip of the hydrofoil

\section{NUMERICAL PREDICTION OF THE CAVITATING TIP VORTEX}

The purpose of the first stage of calculations in the research project, described in this article, was to test and compare different CFD programs and different turbulence models from the point of view of their ability to predict accurately the geometry of the cavitating kernel of the tip vortex. One flow condition was selected for this comparison, namely hydrofoil angle of attack equal to 8 degrees and the velocity of flow equal to $5.2 \mathrm{~m} / \mathrm{s}$. The geometry of the computation domain taken into account in the CFD calculation is shown in Fig. 6 It may be seen that quite a large section of the cavitation tunnel, especially in front of the hydrofoil, was modeled numerically. The inlet confuser was taken into account in the simulations in order to obtain the similar velocity distribution upstream the hydrofoil as in the measurements. Calculations were performed using two commercial CFD programs: Ansys/Fluent v12 and Ansys/CFX. In order to demonstrate the practical accuracy of numerical prediction of the cavitating tip vortex, the authors of calculations were not familiar with the experimental results beforehand. They prepared and performed the calculations using their best experience.

The unstructured computational grid for Fluent is constructed of about 4.7 million of hexahedral elements. The mesh was created in Hexpress/Numeca mesh generator. The density of element distribution is increased near the tunnel walls in order to keep $y=1$. In view of the anticipated presence of the tip vortex the grid had also significantly increased density in the region behind the hydrofoil tip - see Fig. 7. In computations the MUSCL (Monotone Upstream-Centered Schemes for Conservation Laws) scheme was used and 4 turbulence models were tested:

- $\quad$ standard $\mathrm{k}-\varepsilon$ model

- $\mathrm{k}-\varepsilon \mathrm{RNG}$

- $\mathrm{k}-\omega \mathrm{SST}$

- Reynolds Stress Model (RSM)

Boundary conditions were set as follows:

at the inlet plane:

- mass flow rate $437 \mathrm{~kg} / \mathrm{s}$ (it corresponds to velocity at the test section $\sim 5.2 \mathrm{~m} / \mathrm{s}$ )

- total temperature $283 \mathrm{~K}$

- turbulence intensity $1 \%$

- turbulent viscosity ratio 10

- at the outlet plane

- static pressure $15 \mathrm{kPa}$

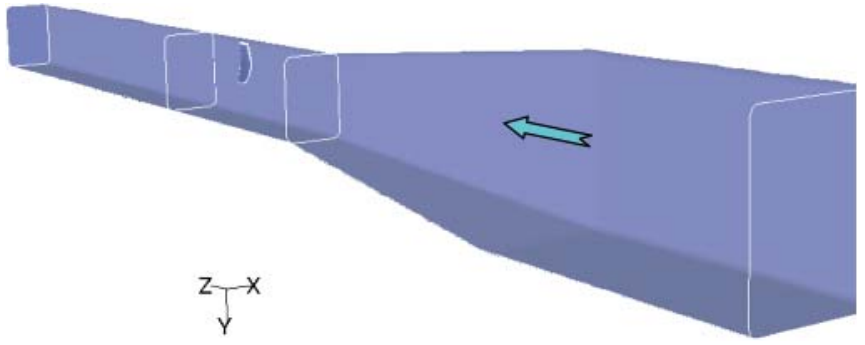

Fig. 6. The domain of flow taken into account in CFD calculations

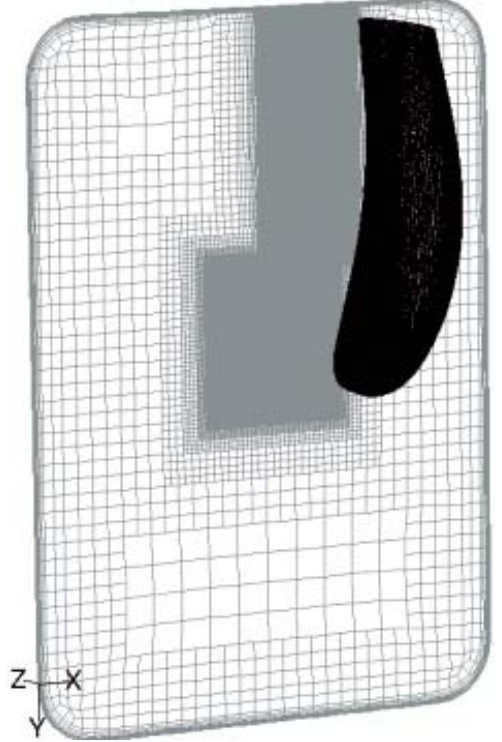

Fig. 7. Discretization of the hydrofoil and the plane behind it used in Fluent 
A mixed two-phase model was used in the calculations of the cavitating flow. Cavitation was determined on the basis of Rayleigh-Plesset equation in Zwart-Gerber-Belamri formulation [7]. The gaseous phase was treated as a compressible medium according to the perfect gas model.

Calculations performed using the Ansys/CFX program were performed on the basis of unstructured grid having about 9 million elements, including about 8.2 million tetrahedral elements and about 0.8 million prismatic elements in the boundary layer. Part of this grid located in the vicinity of the hydrofoil is shown in Fig. 8. The gaseous phase was treated as a incompressible medium in case of Ansys/CFX simulations.

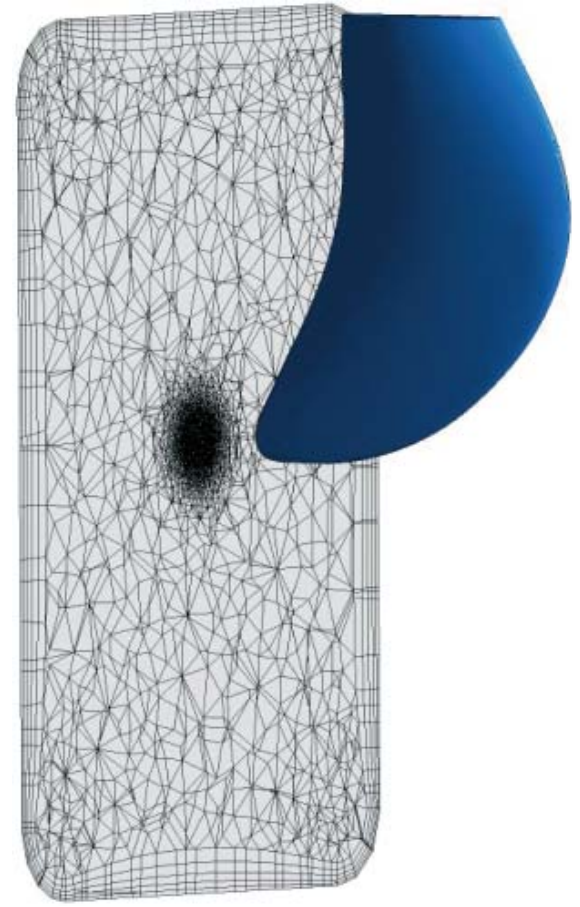

Fig. 8. Discretization of the hydrofoil and plane behind it used in CFX

In the calculations by CFX the same turbulence models were used as in Fluent case.

The comprehensive description of CFD calculations may be found in [4].

\section{COMPARISON OF THE EXPERIMENTAL AND NUMERICAL RESULTS}

\section{Comparison of the registered and calculated geometry of the cavitating tip vortex}

The photograph of the cavitating tip vortex in the analyzed flow condition (angle of attack 8 degrees, velocity of flow 5.2 $\mathrm{m} / \mathrm{s}$ ) is shown in Fig. 9, while the results of corresponding CFD calculations are presented in Figs. 10, 11 and 12. The detailed analysis of the figures leads to the following observations:

- there are significant differences between Fluent and CFX predictions, even when using the same turbulence model; these differences may be attributed to the markedly different structure in the computational grid between both programs,

- similarly important differences may be found in predictions by each of the programs (Fluent or CFX) while using different turbulence models,

- CFX results are much less dependent of the turbulence model than the Fluent ones,

- the differences in performance between Fluent and CFX for the same turbulence models result most likely from the different structures of the computational grids and numerical schemes implemented in the solvers

- $\quad \mathrm{k}-\varepsilon$ RNG turbulence model seems to be the best suited for prediction of tip vortex cavitation and it performs equally well both in Fluent and CFX,

- standard k- $\varepsilon$ turbulence model in Fluent case gives the shortest cavitating zone what is highly related to the dissipative nature of this model

- CFX results for standard k- $\varepsilon$ and SST turbulence model give surprisingly the same results

- both programs predicted some sheet cavitation at the root of the hydrofoil which was not observed in the experiment.

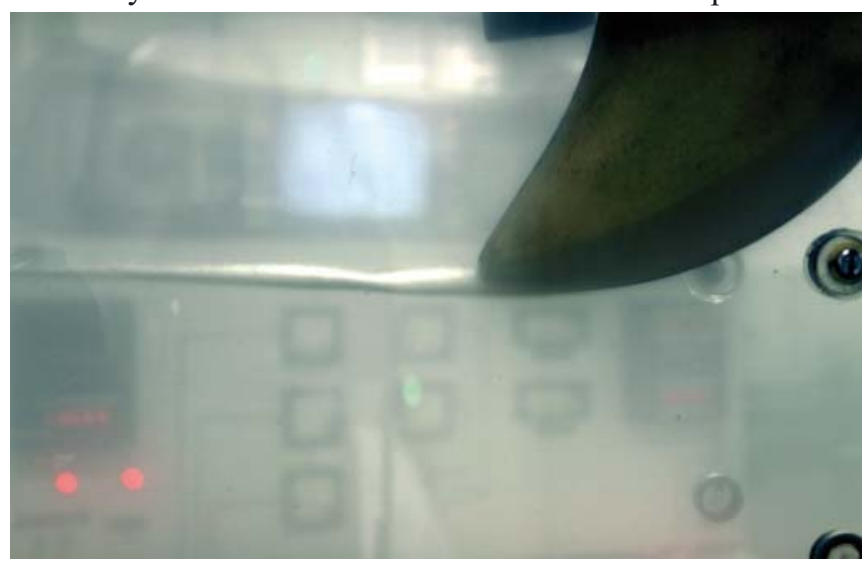

Fig. 9. Photograph of the cavitating tip vortex in the selected flow configuration

\section{Comparison of the measured and calculated velocity field near the cavitating vortex}

The measurements and calculations of the velocity field in the close vicinity of the cavitating tip vortex were performed for the same selected flow condition. The results are presented in the form of velocity vectors in the $\mathrm{X}-\mathrm{Y}$ plane (i.e. plane

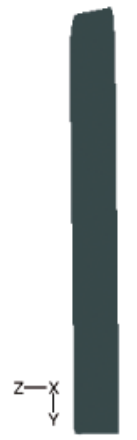

$300 \mathrm{~mm}$

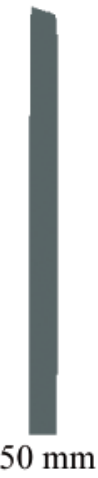

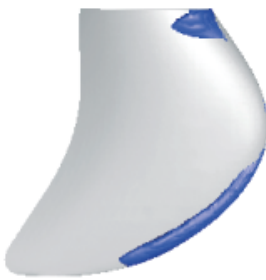

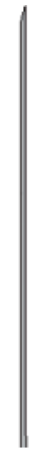

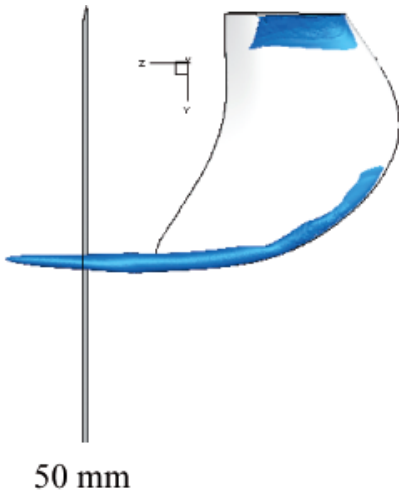

Fig. 10. Calculated cavitation - $k$ - $\varepsilon$ standard turbulence model - Fluent (left) and CFX (right) 

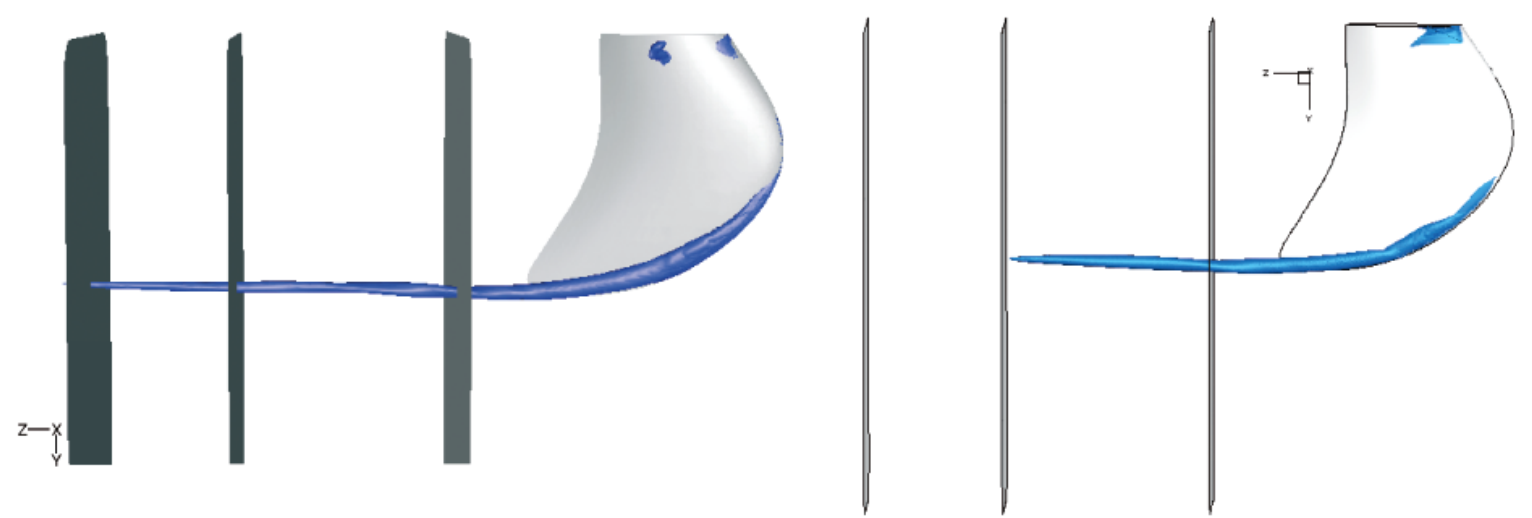

Fig. 11. Calculated cavitation $-k-\varepsilon R N G$ turbulence model - Fluent (left) and CFX (right)
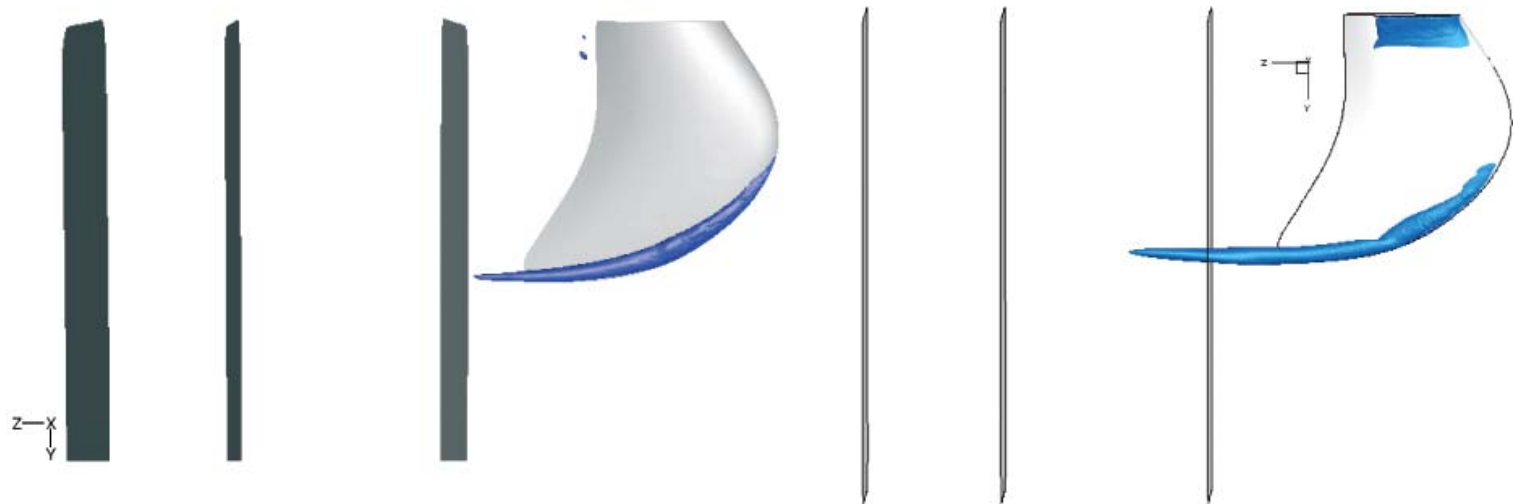

Fig. 12. Calculated cavitation - $k$ - $\omega$ SST turbulence model-Fluent (left) and CFX (right)

perpendicular to the axis of the cavitating vortex) and they are grouped together according to the distance of this plane from the hydrofoil tip. Figs. 13, 14, 15, 16 show the results for 50 $\mathrm{mm}$ distance, Figs 17, 18, 19, 20 - for $200 \mathrm{~mm}$ distance and Figs. 21, 22, 23 and 24 - for $300 \mathrm{~mm}$ distance. The results of measurements are presented (Figs. 13, 17 and 21) according to two different procedures of averaging (left and right section of the Figures) of the velocity field. The processing of experimental data in each flow conditions was done by PIV measurements of approximately 20 to 25 instantaneous velocity fields and their time averaging. Two final types of velocity fields were obtained for each measuring conditions by subtracting either space averaged velocity vector or only the horizontal component of this vector from the time averaged velocity field. The origin of the coordinating system for each PIV intersection distance from hydrofoil was in taken in the center of the cavitating tip vortex. The homogeneous high velocity area in the vicinity of the origin should be analyzed with respect of remarks described in the conclusions section of this article.

Close inspection of the results for the plane located 50 $\mathrm{mm}$ behind the hydrofoil tip leads to several interesting observations:

- measurements indicate presence of two almost equally strong vortex kernels; such a situation may happen in specific flow cases, but in this case it is not confirmed by photographs and by calculations,

- predictions by CFX look almost the same for all turbulence models, what corresponds to the results of calculation of cavitation described above,

- predictions by Fluent depend strongly on the turbulence model,

- predictions by Fluent and CFX agree quite well with each other for k- $\varepsilon$ RNG turbulence model,

- Fluent results show existence of the wake downstream of the hydrofoil, such effect is less visible in prediction by CFX, what arises from the mesh structure.
Analysis of Figs 17 - 20, describing the situation at $200 \mathrm{~mm}$ behind the hydrofoil, may be summarized in the following way: - the measurements indicate the advancing process of concentration and merging of the two initially detected vortex kernels into one,

- calculation by Fluent and CFX indicate the process of turbulent dissipation of vorticity and resulting weakening of the vortex,

- this calculated process of dissipation of turbulent vorticity depends strongly on the model of turbulence; it seems to be overestimated in case of standard $k-\varepsilon$ and $k-\omega$ SST models, what leads to prediction of too short cavitating tip vortex (cf. Figs. 9-12), because the calculated intensity of the vortex falls too rapidly with distance from the hydrofoil,

- the k- $\varepsilon$ RNG turbulence model produces very similar results both in Fluent and CFX, moreover, they agree reasonably with the results of measurements as far as the maximum values of velocity are concerned.

- Fluent results still indicate existence of the wake downstream of the hydrofoil, its interaction with the vortex results in an asymmetric structure of the vortex, it is better shown for k- $\varepsilon$ RNG and SST models (less dissipative than standard k-E).

The situation at $300 \mathrm{~mm}$ behind the hydrofoil tip, shown in Figs. $21-24$, may be summarized in the following way:

- measurements show a single strong vortex of a rather unnatural rectangular cross-section,

- as far as the calculations are concerned, only the results obtained from Fluent with $\mathrm{k}-\varepsilon$ RNG turbulence model produce maximum values of velocity comparable with that determined in the measurements,

- all other calculations predict too intensive dissipation of vorticity, what is confirmed by the cavitation prediction shown in Figs. $10-12$

- the interaction of the tip vortex with the wake is still present in Fluent results. 

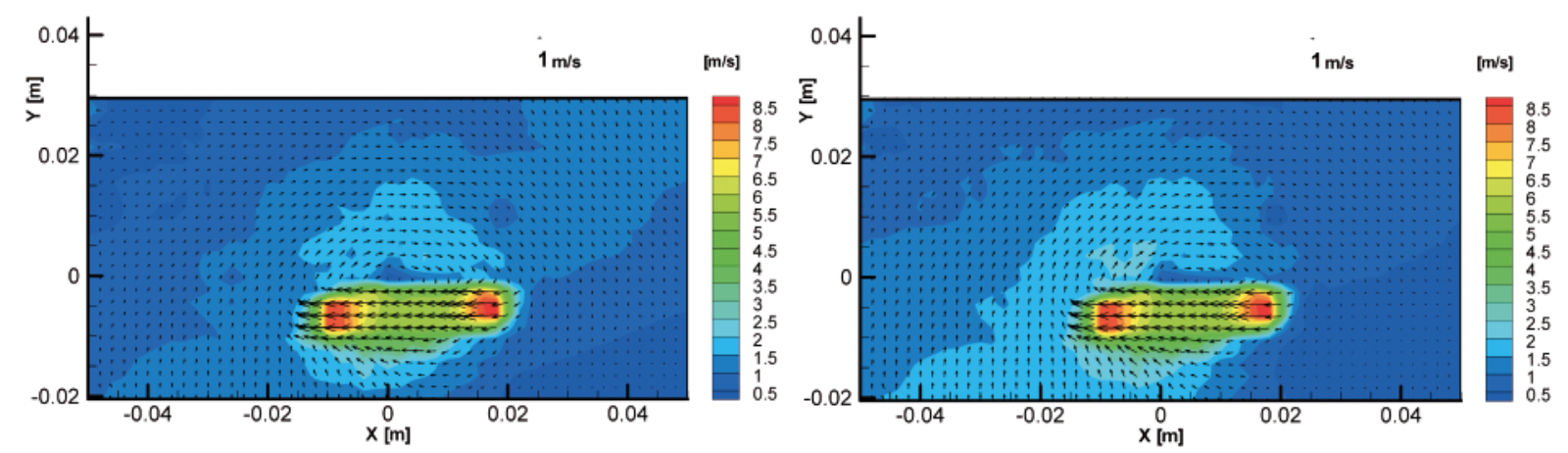

Fig. 13. Measured velocity field in plane the $X-Y$ at the distance $50 \mathrm{~mm}$ behind the hydrofoil tip
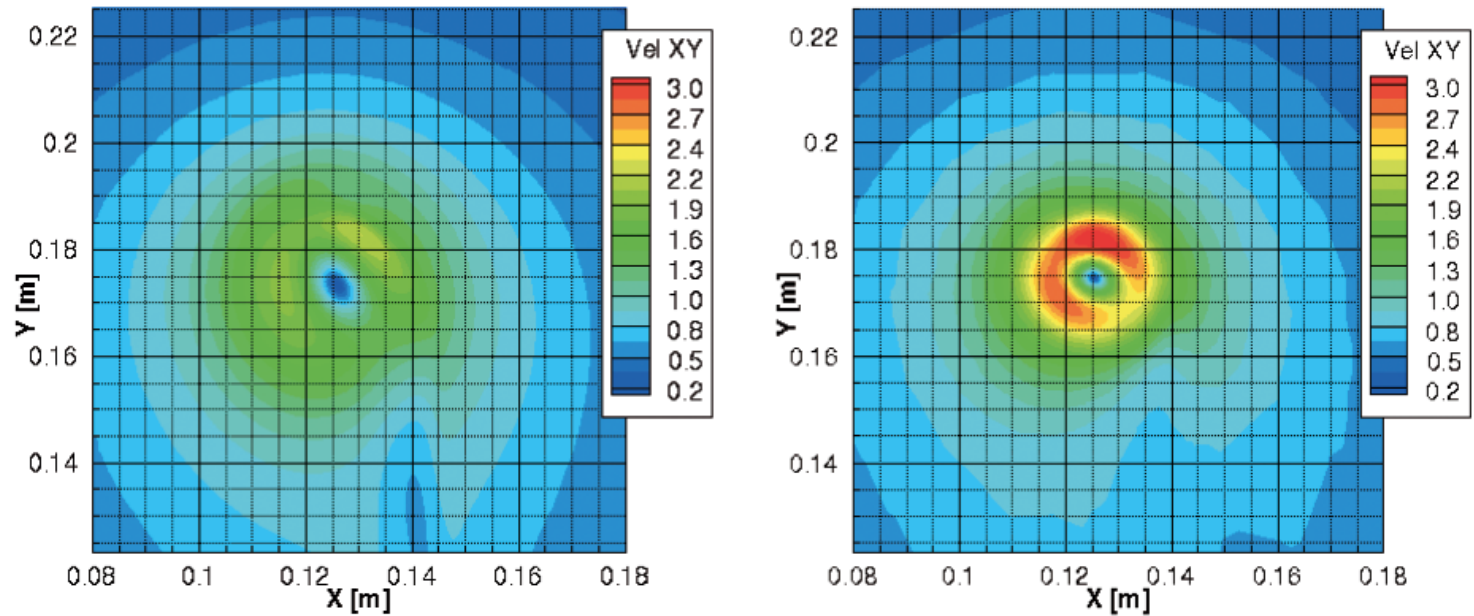

Fig. 14. Calculated velocity field in the plane $X$-Y at the distance $50 \mathrm{~mm}$ behind the hydrofoil tip - $k$ - $\varepsilon$ standard turbulence model - Fluent (left), CFX (right)
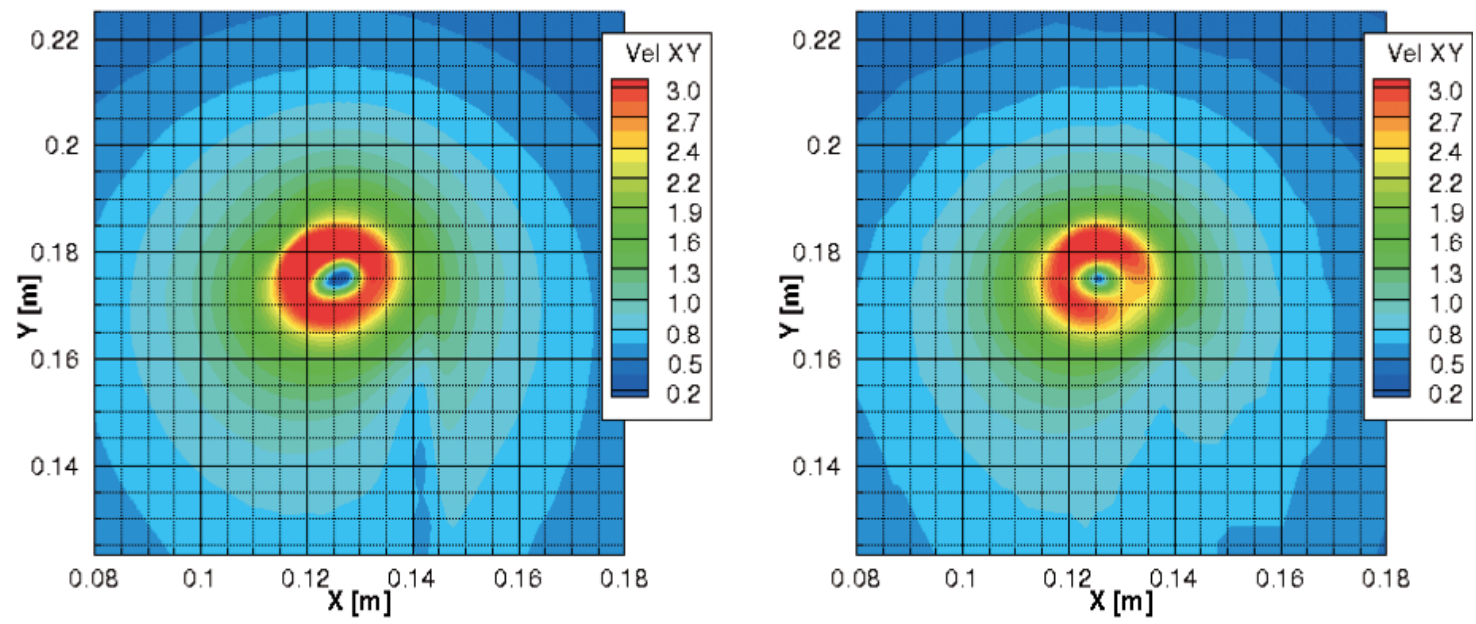

Fig. 15. Calculated velocity field in the plane X-Y at the distance $50 \mathrm{~mm}$ behind the hydrofoil tip - $k$ - $\varepsilon$ RNG turbulence model - Fluent (left), CFX (right)
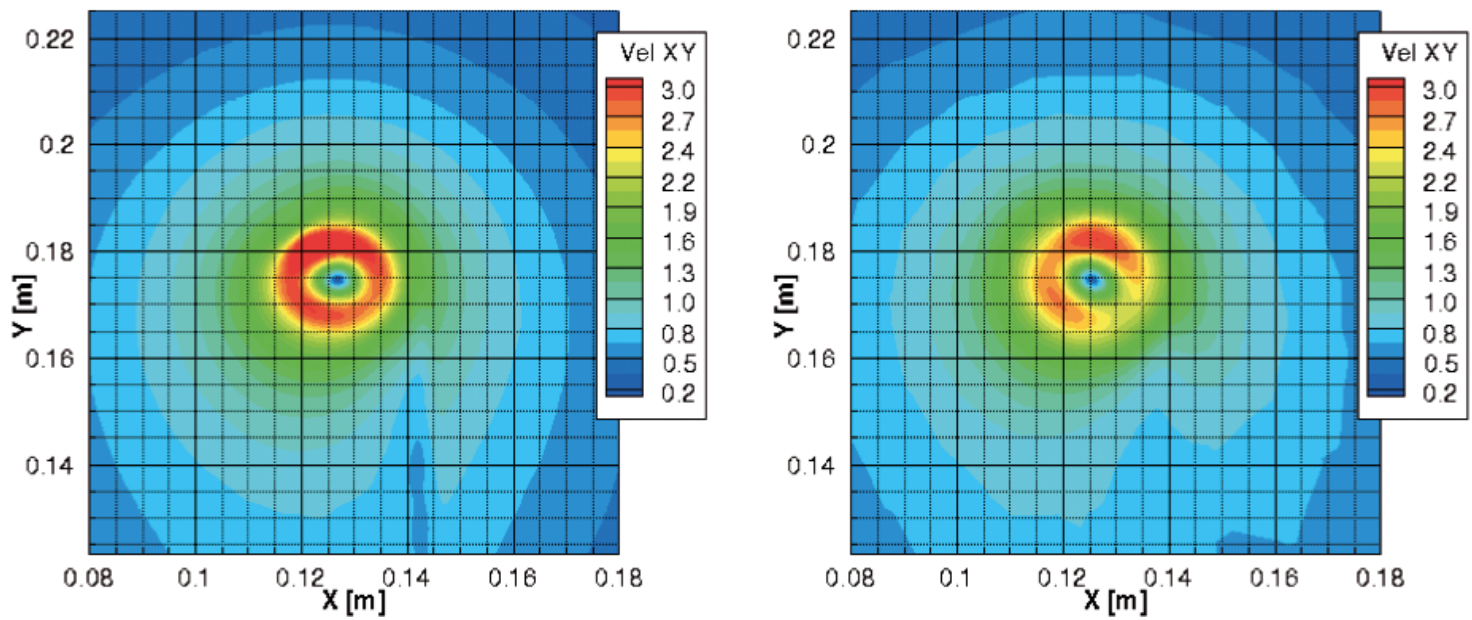

Fig. 16. Calculated velocity field in the plane X-Y at the distance $50 \mathrm{~mm}$ behind the hydrofoil tip - $k$ - $\omega$ SST turbulence model - Fluent (left), CFX (right) 

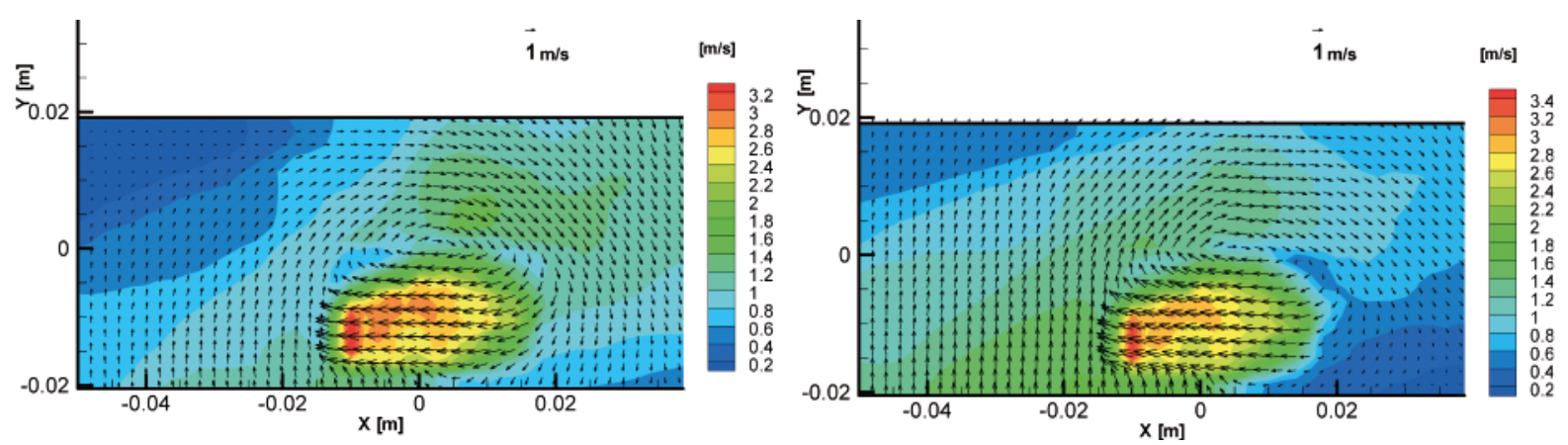

Fig. 17. Measured velocity field in plane $X$-Y at the distance $200 \mathrm{~mm}$ behind the hydrofoil tip
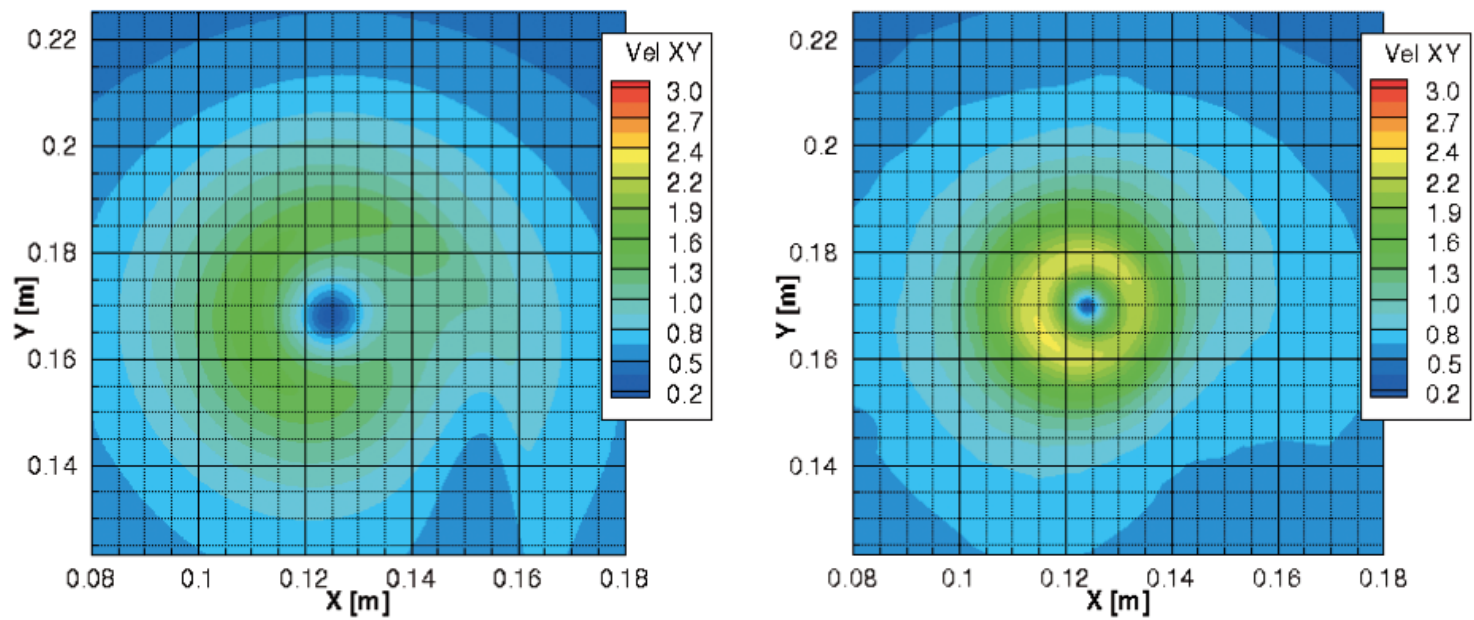

Fig. 18. Calculated velocity field in the plane X-Y at the distance $200 \mathrm{~mm}$ behind the hydrofoil tip $-k$ - $\varepsilon$ standard turbulence model - Fluent (left), CFX (right)
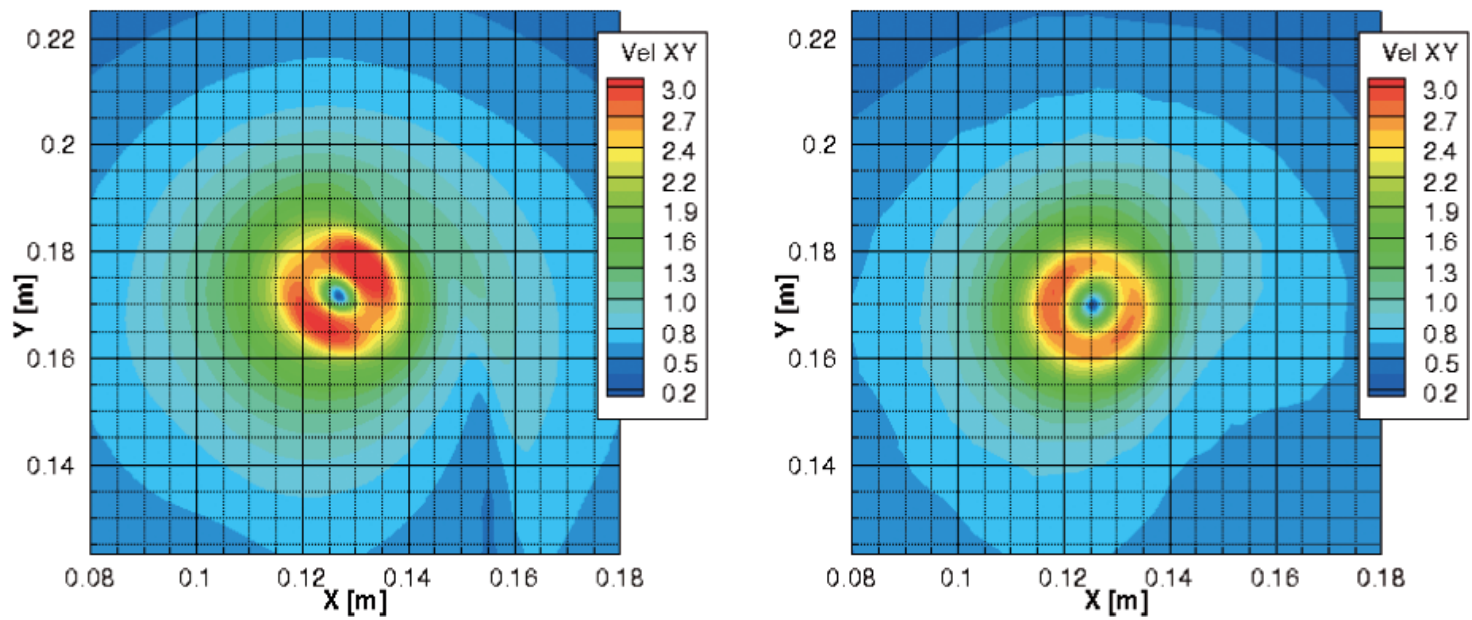

Fig. 19. Calculated velocity field in the plane X-Y at the distance $200 \mathrm{~mm}$ behind the hydrofoil tip $-k-\varepsilon$ RNG turbulence model $-F l u e n t$ (left), CFX (right)
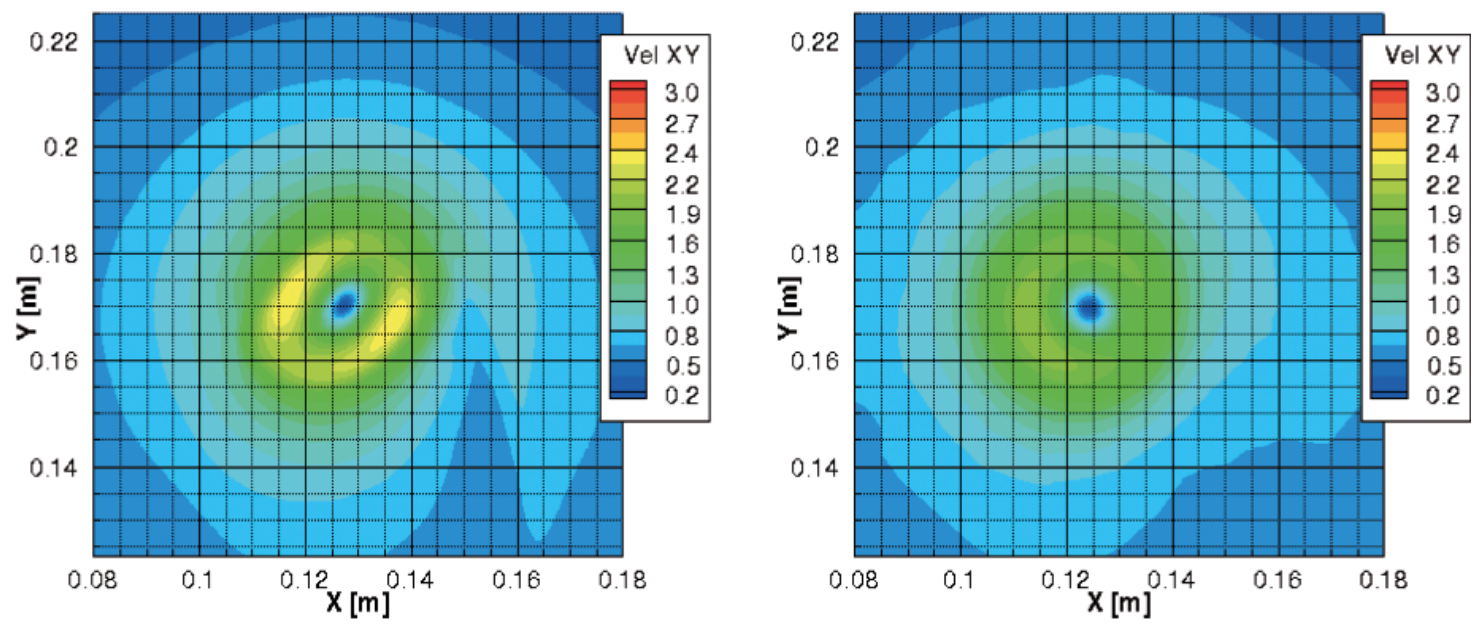

Fig. 20. Calculated velocity field in the plane X-Y at the distance $200 \mathrm{~mm}$ behind the hydrofoil tip - $k$ - $\omega$ SST turbulence model - Fluent (left), CFX (right) 


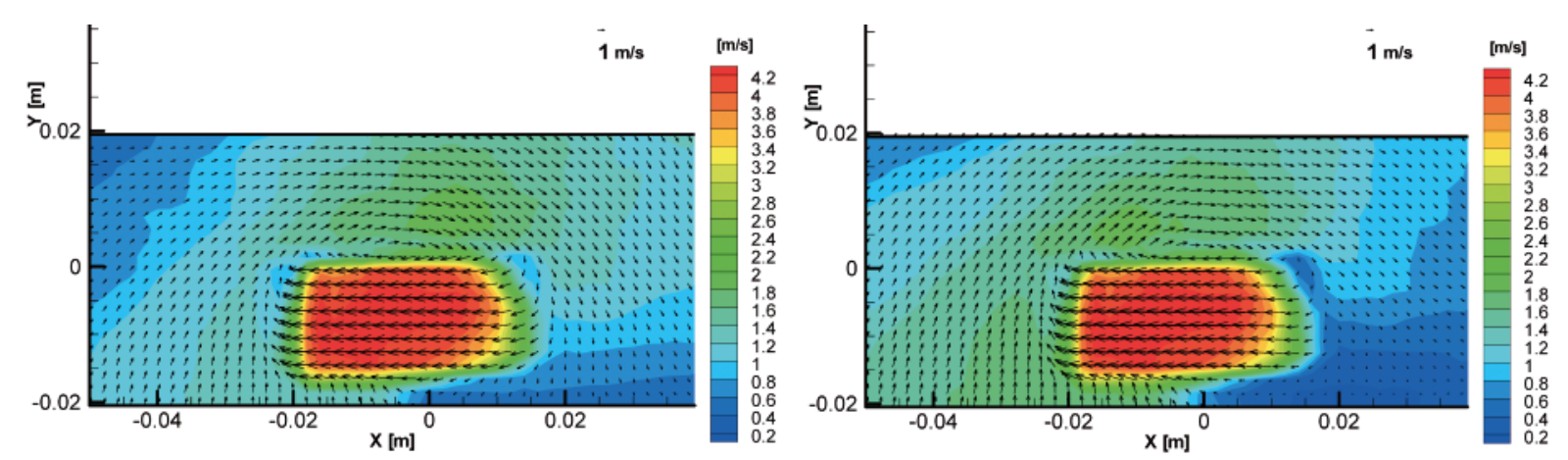

Fig. 21. Measured velocity field in the plane $X-Y$ at the distance $300 \mathrm{~mm}$ behind the hydrofoil tip
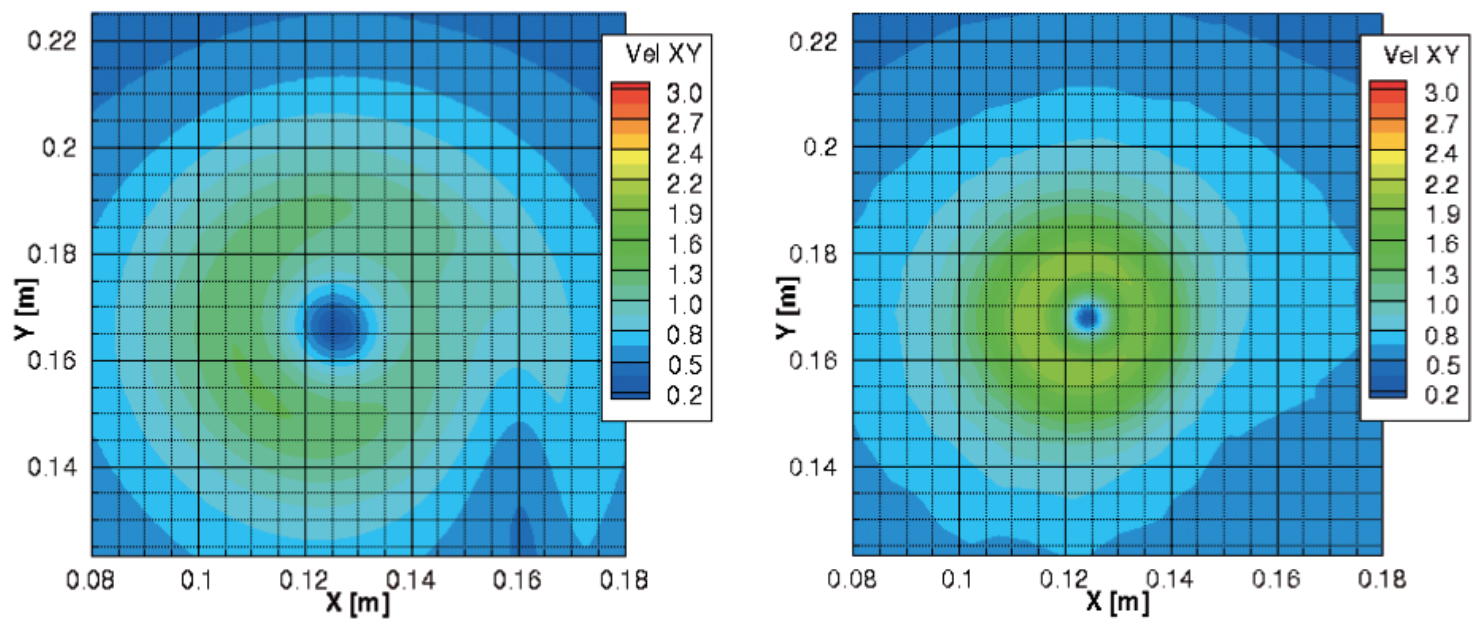

Fig. 22. Calculated velocity field in the plane X-Y at the distance $300 \mathrm{~mm}$ behind the hydrofoil tip $-k$ - $\varepsilon$ standard turbulence model - Fluent (left), CFX (right)
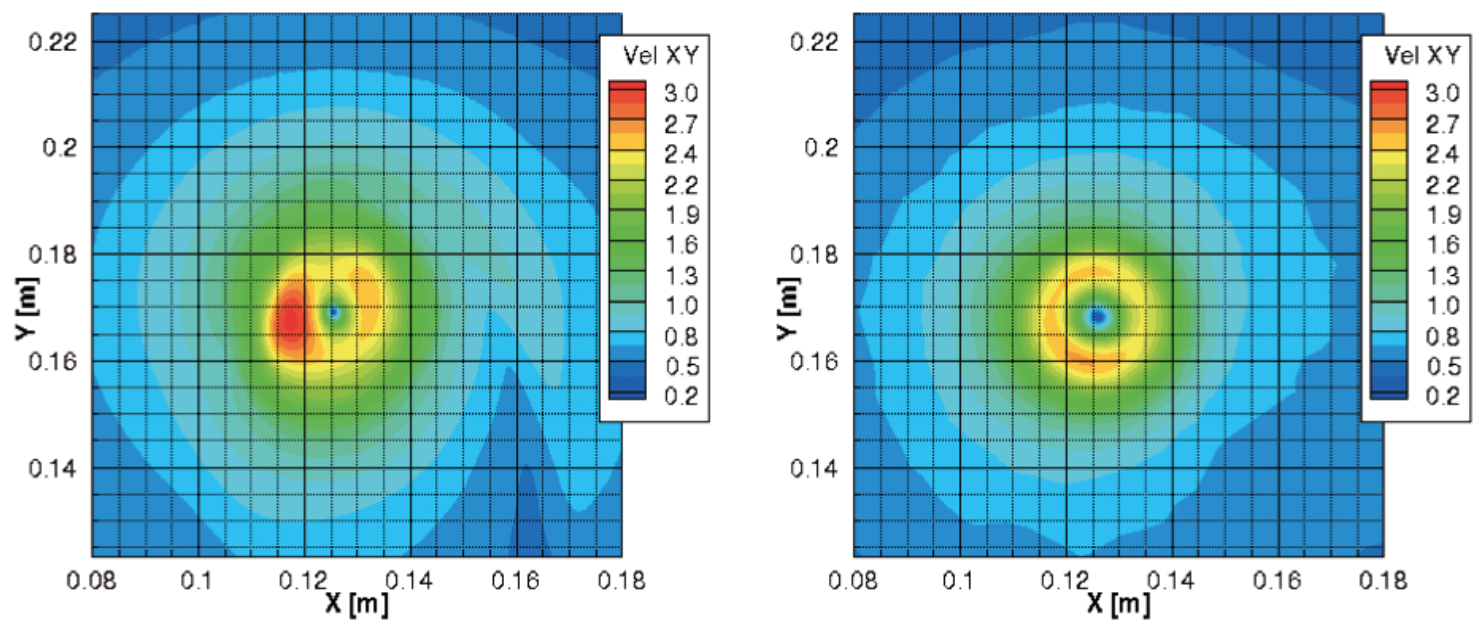

Fig. 23. Calculated velocity field in the plane $X-Y$ at the distance $300 \mathrm{~mm}$ behind the hydrofoil tip $-k-\varepsilon$ RNG turbulence model - Fluent (left), CFX (right)
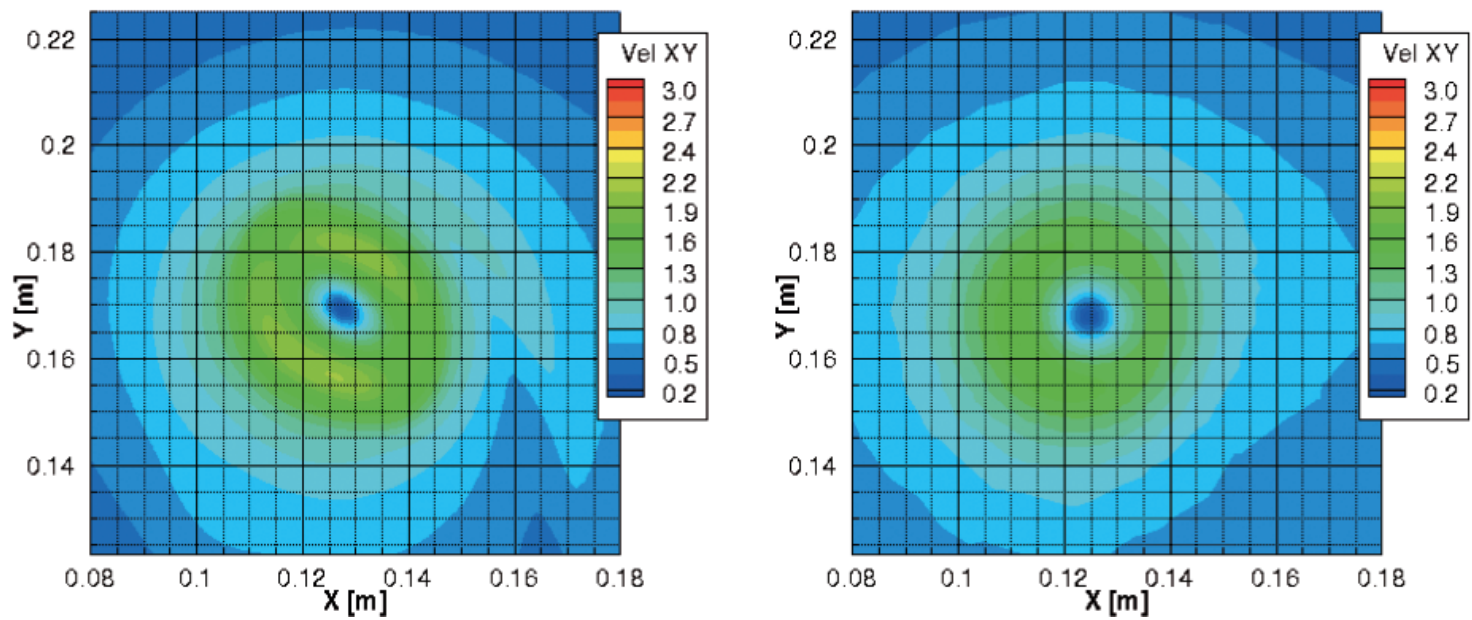

Fig. 24. Calculated velocity field in the plane X-Y at the distance $300 \mathrm{~mm}$ behind the hydrofoil tip - $k$ - $\omega$ SST turbulence model - Fluent (left), CFX (right) 


\section{CONCLUSIONS}

The detailed analysis of the results of measurements, observations and CFD calculations presented in this article leads to the following conclusions:

- the contemporary commercial CFD codes are generally capable of predicting the geometry of the cavitating tip vortices generated by hydrofoils reasonably well,

- the accuracy of CFD prediction of the geometry of the cavitating tip vortex depends strongly on the turbulence models and on the grid structure, hence only the grids constructed especially for vortex-dominated flows should be used, together with turbulence models especially suited for modeling of such flows $[1,2,3,6]$,

- in view of the above presented results the turbulence model $\mathrm{k}-\varepsilon$ RNG seems to be best suited for CFD prediction of tip vortex cavitation, despite the fact that according to [3] the $\mathrm{k}-\omega$ SST performed best in prediction of non-cavitating vortex flows,

- the measurements of the velocity field in the vicinity of the cavitating tip vortex by means of PIV methods seem to be a difficult and challenging task, especially due to the following reasons:

○ unsteady oscillations of the cavitating kernel of the vortex,

○ uncontrolled content of cavitation nuclei (i.e. gas and vapour filled micro-bubbles) carried by the flowing water,

- shading of part of the measuring plane by the cavitating kernel,

- difficulties in homogeneous PIV seeding due to the large volume of fluid inside the cavitation tunnel and complex flow conditions near cavitating tip vortex (centrifugal force acting on seeding particles)

- due to the above listed reasons the velocity distribution predicted numerically at the following sections is significantly different from the measurements.

\section{Acknowledgement}

The research described in this article has been conducted with the support of the Research Grant No. N N504 088738 of the Polish Ministry of Science and Higher Education.

\section{BIBLIOGRAPHY}

1. Dymarski P., Szantyr J., Flaszyński P., Kraskowski M., Biernacki R.: Modelling of Tip Vortex Behind a Blade using Different Turbulence Models and Different RANSE Solvers, Proc. of the $11^{\text {th }}$ Numerical Towing Tank Conference, Brest, France, September 8-10, 2008

2. Flaszyński P., Szantyr J., Dymarski P., Kraskowski M.: Numerical Prediction of Vortex Generated by a Hydrofoil, Proc. Of the International Symposium on Marine Propulsors, Trondheim, Norway, June 22-24, 2009

3. Flaszyński P., Szantyr J.: Biernacki R., Dymarski P., Kraskowski M.: A Method for the Accurate Numerical Prediction of the Tip Vortices Shed from Hydrofoils, Polish Maritime Research No. 2(65), Vol. 17, 2010, pp.10-17

4. Flaszyński P., Tesch K.: Research Report-Task 2 Calculations for the Selected Flow Configuration Using Different Cavitation Models (in Polish), Gdansk University of Technology 2011

5. Suchecki W., Alabrudziński S.: Research Report - Task 1 Experimental Measurements of the Geometry of the Cavitating Vortex Kernel and Velocity in its Close Vicinity (in Polish), Warsaw University of Technology 2011

6. Szantyr J., Biernacki R., Flaszyński P., Dymarski P., Kraskowski M.: An Experimental and Numerical Study of The Vortces Generated by Hydrofoils, Polish Maritime Research No. 3(61), Vol. 16, 2009, pp.11-17

7. Zwart P.J., Gerber A.G., Belamri T.: A Two-Phase Flow Model for Predicting Cavitation Dynamics, Fifth International Conference on Multiphase Flow, Yokohama, Japan, 2004

\section{CONTACT WITH THE AUTHORS}

J.A. Szantyr, Prof. e-mail: jas@pg.gda.pl

P. Flaszynski, Ph.D. e-mail: pflaszyn@pg.gda.pl

K.Tesch,Ph.D. e-mail: krzyte@pg.gda.pl

Faculty of Mechanical Engineering

Gdansk University of Technology

Narutowicza 11/12

80-231 Gdańsk, POLAND

W. Suchecki,Ph.D. email: suchecki@pl.onet.pl

S. Alabrudziński, Ph. D. e-mail: salabrudzinski@pw.plock.pl Faculty of Civil Enginering,

Mechanics and Petrochemistry

Warsaw University of Technology

Łukasiewicza 17

09-400 Płock, POLAND 